\title{
Impact Dynamic Properties and Energy Evolution of Damaged Sandstone Based on Cyclic Loading Threshold
}

\author{
Qiangqiang Zheng $\mathbb{D}^{1,2}$, Hao Hu $\mathbb{D}^{1},{ }^{1}$ Anying Yuan, ${ }^{1}$ Mengyao Li, ${ }^{1}$ Haibo Wang, ${ }^{1,2}$ \\ Mengxiang Wang, ${ }^{1,2}$ Qi Zong, ${ }^{1,2}$ and Shouyang Zhang ${ }^{1,2}$ \\ ${ }^{1}$ State Key Laboratory of Mining Response and Disaster Prevention and Control in Deep Coal Mines, \\ Anhui University of Science and Technology, Huainan, Anhui 232001, China \\ ${ }^{2}$ School of Civil Engineering and Architecture, Anhui University of Science and Technology, Huainan, Anhui 232001, China
}

Correspondence should be addressed to Hao Hu; 2017040@aust.edu.cn

Received 29 October 2020; Accepted 7 November 2020; Published 29 November 2020

Academic Editor: Xuesheng Liu

Copyright (c) 2020 Qiangqiang Zheng et al. This is an open access article distributed under the Creative Commons Attribution License, which permits unrestricted use, distribution, and reproduction in any medium, provided the original work is properly cited.

\begin{abstract}
Rocks in deep coal mines are usually in varying degrees of damage state before they are destabilized by impact loads such as rock bursts. For the problem of the mechanical properties and energy evolution of damaged rocks under impact loads, the authors use static loads with different cyclic load thresholds to act on sandstone specimens to make them in distinct degrees of damage. Then, the rock mechanics system (MTS-816) and the Split Hopkinson pressure bar (SHPB) are employed to perform uniaxial compression and impact dynamics tests on sandstones with different degrees of damage. The results show that, from the perspective of mechanical properties, the uniaxial compressive strength and dynamic compressive strength of the damaged sandstone gradually decrease with the increase of the upper limit of the cycle threshold and both obey the growth law of the quadratic function, and the dynamic strength increase factor (DIF) also decreases with the increase of the cyclic load threshold. In terms of energy, with the increment of the cyclic load threshold, the number of cracks in the damaged sandstone is large and the scale is enormous. Due to the effect of cracks, when the incident energy is a fixed value, the transmission energy decreases with the increase of the damage degree and the change law of the reflection energy is the opposite. The systematic study of the dynamic mechanical properties and energy evolution law of the damaged sandstone provides some reference for the prevention and mechanism research of rock bursts.
\end{abstract}

\section{Introduction}

With the increasing consumption of coal resources year by year, dynamic disasters such as rock bursts and roof disasters induced by increased coal mining depth and mining speed have occurred frequently [1-3], causing irreparable economic losses and casualties and further restricting the development of energy economy. The frequent occurrence of dynamic disasters such as rock bursts and roof fall accidents is closely related to the mechanical properties, geological structure, and rock formation activity law of the rock in the stope [4-6], among which the mechanical properties of the rock are the most basic and core part of the study of dynamic disaster prevention and control [7]. Based on the above viewpoints, many scholars have carried out a lot of research work, not only to study the static mechanical properties of rocks but also to analyze the dynamic mechanical properties. These fruitful research results are of great significance for the prevention and control of dynamic disasters.

The earliest recorded rock burst occurred in the Stafford Coalfield in England in 1738, but it was not until the 20th century that the rock burst became a research field systematically. Based on the static mechanics of rock, many scholars have researched the prevention and treatment of rock burst using laboratory tests, numerical simulations, and on-site engineering monitoring. Khademian and Ugur [8] used numerical simulation to simulate the initial quasistatic response of rock burst under compression and shear, further providing a calculation framework for studying rock burst events. Tian et al. [9] explored the impact tendency of the 
stope under the static load disturbance of multiseam mining through similar model tests and obtained the damage range of the roof rock layer and the range of impact of rock burst disaster during multiseam mining. Simser [10] took an engineering case as the research object, analyzed the effectiveness of the hydraulic support installation speed on the static disturbance of the rock mass, and based on this explored a multilayer method for mitigating rock burst. Cai et al. [11] analyzed the relationship between stress, strain, and energy of roadway surrounding rock under static load, established a damaged mechanical model of rock mass under load, and proposed a quantitative evaluation index of coal rock burst pressure tendency. Gale [12] comprehensively discussed the relationship between the rock burst and the stress and the stope rock mass under static load. Centered on the mechanism of rock burst disasters, in addition to the static mechanical properties of rocks, the dynamic mechanical properties of rocks are also a factor that cannot be ignored. Therefore, many scholars have analyzed the mechanism of rock burst disasters based on the dynamic mechanical response of rocks. Wang et al. [13] independently developed the test simulation device to study the rock burst resistance of the tunnel under the dynamic load of blasting load and rock burst. Zhou et al. [14] used an improved SHPB to study the dynamic mechanical properties of sandstone under different strain rates, and geometrical fractal statistics of the fragmentation of the sandstone specimen under impact load to obtain the dynamic compressive strength and energy dissipation law of sandstone under different strain rates are obtained. Rehbock-Sander and Jesel [15] monitored the dynamic mechanical behavior of rock masses in tunnels and introduced the prediction and prevention measures of rock burst disasters. Sainoki et al. [16] used the method of blast loading to study the mechanism of dynamic disaster-induced rock burst; in addition, it also made a more precise division of the impact range of rock burst. The above-mentioned scholars studied the static mechanical properties and dynamic mechanical properties of rocks based on the mechanism and prevention of rock burst disasters. However, the occurrence of dynamic disasters in coal mines is the result of multifactor coupling [17]. The static mechanical properties and dynamic mechanical properties of the rock are studied separately. The rock in the stope is affected by burial depth and excavation activities. Before the rock burst accident occurred, the rock has been damaged by repeated static load disturbances to varying degrees [18]. Therefore, it is not comprehensive to consider the static mechanical properties of rocks and the dynamic response of rocks separately under disasters. The dynamic mechanical response of damaged rock mass after being disturbed by a load is the main mechanical factor affecting the occurrence of dynamic disasters such as rock burst. Therefore, the systematic study of the dynamic mechanical properties of the damaged rock mass after load disturbance has some impetuses for the analysis of the mechanism of rock burst accidents.

Rocks buried deep in coal mines are usually in varying degrees of damage due to the excavation activities of adjacent coal seams or stopes [19]. At this time, the strength of the rock is lower than the strength of the rock when it is not disturbed. Within the range of impact of mining activities, when the stratum structure is damaged or the stress is in an abnormal state, the energy storage structure of the local rock is instantly unstable on a large scale and releases energy to induce shock pressure disaster [20]. Therefore, before studying the dynamic response of the rock burst disaster, the damage degree of the rock must be fully considered.

For the sake of exploring the dynamic response and energy evolution of rocks when dynamic disasters such as rock burst in deep coal mines occur, the authors fully considered the sequence and compendious effect of static load and dynamic load. Firstly, based on the Kaiser effect of the rock, the cyclic loading and unloading are carried out under the static load with different load thresholds as the upper limit of cycle, so that the rock is in different degree of damage state. Then, the uniaxial compressive strength of rock specimens with distinct degrees of damage is measured, and the variation between the stress reduction amplitude of the damaged rock and the cyclic load threshold is analyzed. Finally, based on the static mechanical properties of the damaged rock, the SHPB is used to carry out impact dynamic tests to study the dynamic mechanical properties; energy evolution laws and rock crushing energy density of rocks with different damage levels under impact load provide useful theoretical support for the mechanism research and prevention of rock burst in deep coal mines.

\section{Test Equipment and Test Plan}

2.1. Preparation of Test Pieces. The rock required for this test is taken from the rock roadway of a mine in Huainan mining area by in situ sampling method, and the rock sample belongs to sandstone. After cutting and grinding, according to the standards of the International Society for Rock Mechanics and Rock Engineering, a cylindrical sample with a size of $\Phi 50 \mathrm{~mm}^{*} \mathrm{~h} 100 \mathrm{~mm}$, which means that diameter * height is $50 \mathrm{~mm}^{*} 100 \mathrm{~mm}$, is prepared to measure the static mechanical strength of the rock. In addition, a cylindrical test piece with a size of $\Phi 50 \mathrm{~mm}^{*} h 25 \mathrm{~mm}$ is needed to measure the dynamic mechanical properties of the sandstone. The nonparallelism of the two ends of the test piece is less than $0.05 \mathrm{~mm}$, and the flatness error of the end face is controlled below $0.02 \mathrm{~mm}$. Some sandstone test pieces are shown in Figure 1. Before starting the uniaxial loading test and impact dynamics test, apply petroleum jelly evenly on both ends of the test piece, to reduce the end effect of the two ends of the test piece and the friction effect between the device and the equipment.

2.2. Experimental Equipment and Test Plan. The static loading equipment and dynamic loading equipment used in this test are MTS-816 rock mechanics test system and an SHPB test system with a diameter of $50 \mathrm{~mm}$. The above two test types of equipment are shown in Figures 2 and 3, respectively. MTS-816 rock mechanics test system performs uniaxial compressive strength test and static cyclic damage test on sandstone specimens, both the uniaxial compressive 


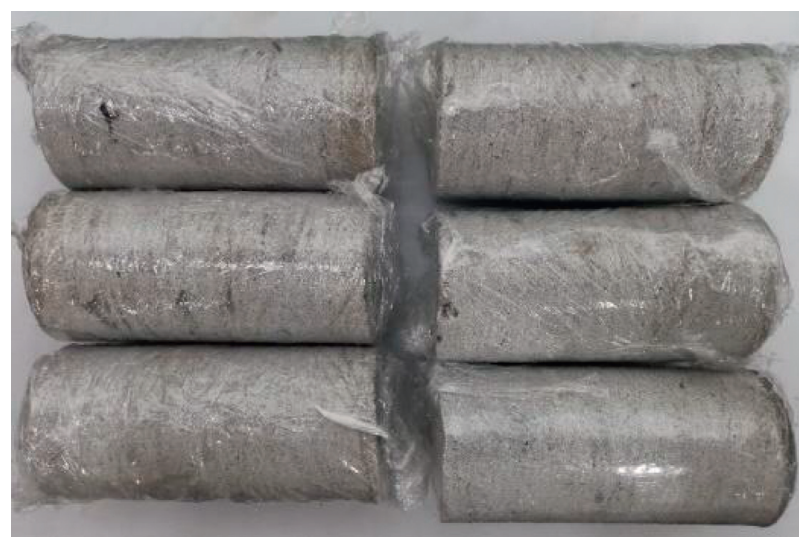

FIgURE 1: Some sandstone samples taken from coal mine.

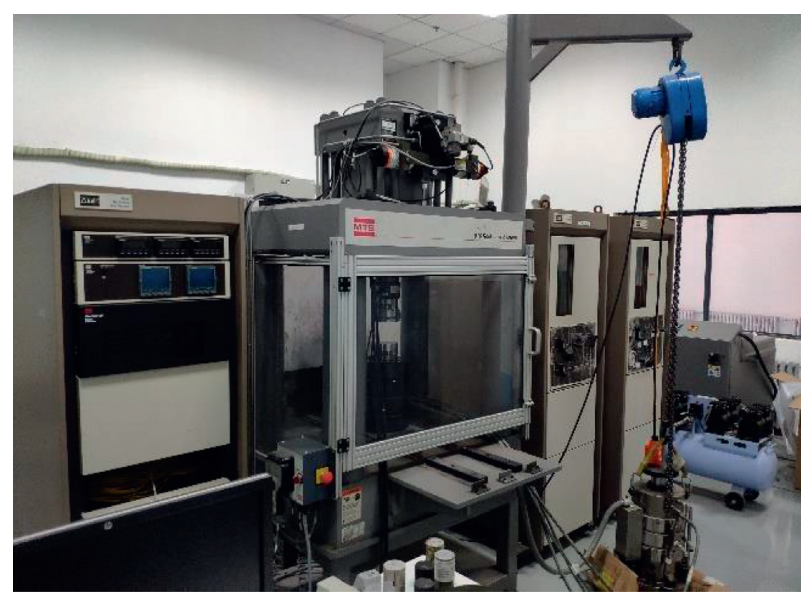

FIgURE 2: Rock mechanics test system.

strength test and the cyclic loading and unloading test adopt the force-time loading method, and the loading rate is $0.5 \mathrm{kN} / \mathrm{s}$. The SHPB test system performs impact dynamic test on damaged sandstone.

First, a static mechanical experiment is performed to determine the strength of the sandstone specimen, and the average compressive strength of the sandstone specimen is determined as $\sigma_{b}$. Then, the sandstone specimens are treated with different degrees of damage with different cycle threshold loads, which is $0.2 \sigma_{b}, 0.4 \sigma_{b}, 0.6 \sigma_{b}$, and $0.8 \sigma_{b}$, respectively. Finally, three different impact air pressures of $0.4 \mathrm{MPa}, 0.5 \mathrm{MPa}$, and $0.6 \mathrm{MPa}$ are selected to perform dynamic mechanical properties of sandstone damaged by the cyclic static load which are tested under different strain rates.

\section{Basic Principle of Dynamic Mechanics Experiment and Verification of Stress Balance}

In the SHPB test, the authors use the three-wave method to analyze the dynamic mechanical properties of the sandstone specimen. The sandstone specimen is placed between the incident bar and the transmission bar. It is assumed that, during the dynamic loading process, any plane in the sandstone specimen remains flat, and there is only uniformly distributed axial stress in any cross section. For ease of calculation, the stress wave emission direction along the incident bar to the transmission bar is defined as positive. The calculation methods of dynamic mechanical parameters of the sandstone specimen including dynamic stress, dynamic strain, and strain rate are shown in equations (1), (2), and (3), respectively. According to these dynamic mechanical performance data, the energy relationship of the sandstone under dynamic load can also be analyzed. Ignoring the energy loss between the bars and the specimen, the high-pressure gas energy is first converted into incident energy. When the incident energy $W_{i}$ acts on the sandstone specimen, part of the energy is converted into reflected energy $W_{r}$, another part is absorbed by the energy absorption device through the transmission bar, and the rest is mainly absorbed by the sandstone, which is used to break up the sandstone specimen and dissipate it in the form of energy. In the SHPB experiment, the incident energy $W_{i}$, the transmitted energy $W_{t}$, and the reflected energy $W_{r}$ of the sandstone under the impact load can be calculated according to equations (4), (5), and (6), respectively:

$$
\begin{aligned}
\sigma & =\frac{A E}{2 A_{0}}\left(\varepsilon_{i}+\varepsilon_{r}+\varepsilon_{t}\right), \\
\varepsilon(t) & =\frac{C_{0}}{l_{0}} \int_{0}^{t}\left(\varepsilon_{i}-\varepsilon_{r}-\varepsilon_{t}\right) \mathrm{d} t, \\
\dot{\varepsilon} & =\frac{C_{0}}{l_{0}}\left(\varepsilon_{i}-\varepsilon_{r}-\varepsilon_{t}\right), \\
W_{i}(t) & =A E C_{0} \int_{0}^{t} \varepsilon_{i}^{2}(t) \mathrm{d} t, \\
W_{r}(t) & =A E C_{0} \int_{0}^{t} \varepsilon_{r}^{2}(t) \mathrm{d} t, \\
W_{t}(t) & =A E C_{0} \int_{0}^{t} \varepsilon_{t}^{2}(t) \mathrm{d} t,
\end{aligned}
$$

where $C_{0}$ is the longitudinal wave velocity of the three bars, $\mathrm{m} / \mathrm{s} ; \varepsilon_{i}, \varepsilon_{r}$, and $\varepsilon_{t}$ are the strains of the incident, reflected, and transmitted waves propagating independently in the bars; $l$ is the height of the sandstone specimen along the axis; $A_{0}$ is the cross-sectional area of the sandstone, $\mathrm{m}^{2} ; A$ is the crosssectional area of the three bars, $\mathrm{m}^{2} ; E$ is Young's modulus of the three bars; $\varepsilon_{i}(t), \varepsilon_{r}(t)$, and $\varepsilon_{t}(t)$ are the strains of the incident, reflected, and transmitted waves on the three bars at time $t$, respectively.

Ignoring the energy consumed between the contact surface of the sandstone and the pressure bar during the loading process, the calculation method of the energy $W_{s}$ absorbed by the specimen under impact loading is shown in equation (7):

$$
W_{s}(t)=W_{i}(t)-W_{r}(t)-W_{t}(t) .
$$

Among the dynamic mechanical energy of sandstone, $W_{s}$ is the energy that can best reflect the complete sandstone 


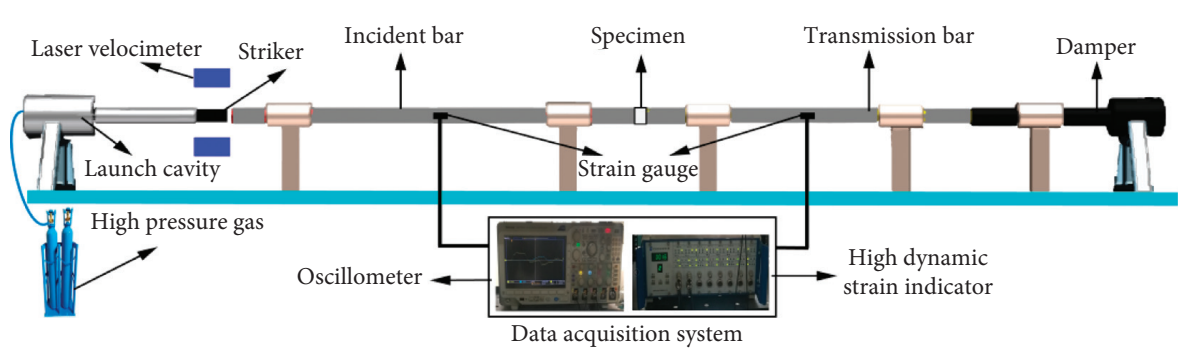

Figure 3: Split Hopkinson pressure bar test system.

specimen when it is broken into fragments by impact load. In addition, due to the inevitable dimensional errors during the processing of the test piece, in order to reduce the error caused by the size difference of the test piece as much as possible, the energy absorbed when the unit volume of rock is crushed under the impact load, that is, the energy consumption density $\omega_{s}$, is introduced:

$$
\omega_{s}=\frac{W_{s}}{V_{s}} .
$$

In the formula, $V_{s}$ is the volume of the sandstone specimen.

Previously, it has been assumed that any plane in the sandstone specimen remains flat during the impact loading process. At any time during the loading process, the force model of a microelement segment in the specimen is simplified as shown in Figure 4.

Supposing the homogeneous cylindrical specimen under axial stress $\sigma_{X}(X, t)$, the axial strain of sandstone is $\varepsilon_{X}$; in addition, due to the Poisson effect of the material, the specimen must also have vertical strains $\varepsilon_{Y}$ and $\varepsilon_{Z}$ at the same time:

$$
\begin{gathered}
\varepsilon_{X}=\frac{\partial u_{X}}{\partial_{X}}=\frac{\sigma_{X}(X, t)}{E}, \\
\varepsilon_{Y}=\frac{\partial u_{Y}}{\partial_{Y}}=-\mu \varepsilon_{X}(X, t), \\
\varepsilon_{Z}=\frac{\partial u_{Z}}{\partial_{Z}}=-\mu \varepsilon_{X}(X, t),
\end{gathered}
$$

where $u_{X}, u_{Y}$, and $u_{Z}$ are the displacement components in the $X$-axis, $Y$-axis, and $Z$-axis directions, respectively, and $\mu$ is Poisson's ratio of the sandstone specimen.

Since $\varepsilon_{X}$ is only a function related to $X$ and $t$ and has no relationship with $Y$ and $Z$, the corresponding displacements $\varepsilon_{Y}$ and $\varepsilon_{Z}$ are integrated, respectively, to obtain the axial displacements $u_{Y}$ and $u_{Z}$. Then, the derivative of the axial displacement is calculated twice to obtain the velocity $v_{Y}$ and $v_{Z}$ of the particle moving perpendicular to the axis and the acceleration $a_{Y}$ and $a_{Z}$ of the particle, respectively:

$$
\begin{gathered}
u_{Y}=-\mu Y \varepsilon_{X}=-\mu_{Y} \frac{\partial u_{X}(X, t)}{\partial X}, \\
u_{Z}=-\mu Z \varepsilon_{X}=-\mu Z \frac{\partial u_{X}(X, t)}{\partial X},
\end{gathered}
$$

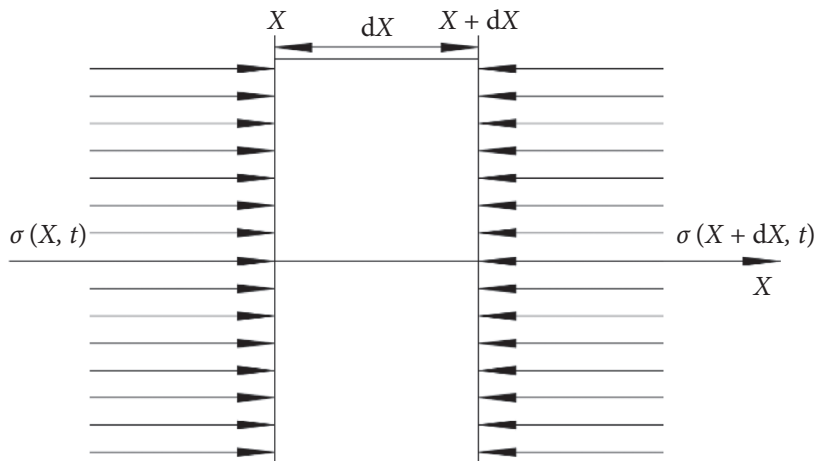

FIgURE 4: Stress model of sandstone microelement segment.

$$
\begin{gathered}
v_{Y}=\frac{\partial u_{Y}}{\partial t}=-\mu Y \frac{\partial \varepsilon_{X}}{\partial t}=-\mu Y \frac{\partial v_{X}}{\partial t}, \\
v_{Z}=\frac{\partial u_{Z}}{\partial t}=-\mu Y \frac{\partial \varepsilon_{X}}{\partial t}=-\mu Z \frac{\partial v_{X}}{\partial t}, \\
a_{Y}=\frac{\partial v_{Y}}{\partial t}=-\mu Y \frac{\partial^{2} \varepsilon_{X}}{\partial^{2} t}=-\mu Y \frac{\partial^{2} v_{X}}{\partial t \partial X}, \\
a_{Z}=\frac{\partial v_{Z}}{\partial t}=-\mu Z \frac{\partial^{2} \varepsilon_{X}}{\partial^{2} t}=-\mu Z \frac{\partial^{2} v_{X}}{\partial t \partial X} .
\end{gathered}
$$

From equations (14), (15), (16), and (17), the kinetic energy per unit volume perpendicular to the sandstone axis is shown in equation (18).

$$
\frac{1}{A_{0} \mathrm{~d} X} \int \frac{1}{2} \rho_{0}\left(v_{Y}^{2}+v_{Z}^{2}\right) \mathrm{d} X \mathrm{~d} Y \mathrm{~d} Z=\frac{1}{2} \rho_{0} v^{2} r_{g}^{2}\left(\frac{\partial \varepsilon_{X}}{\partial t}\right)^{2} \text {. }
$$

In the formula, $r_{g}$ is the radius of gyration of the sandstone cross section facing the $X$-axis.

It can be seen from Figure 4 that there is a pair of statically balanced force $A_{0} \sigma$ and a nonstatically balanced force $A_{0}(\partial \sigma / \partial X) \mathrm{d} X$ in the sandstone microelements. From the perspective of energy, the axial kinetic energy of the microelement body comes from the work done by the nonstatic balancing force, and the work done by the static balance force is converted into the microelement strain increase energy and the kinetic energy perpendicular to the axial direction. Because the movement of the sandstone specimen is bound by the incident bar and the transmission bar, the axial kinetic energy will be gradually transferred to 
the elastic bar and will eventually be dissipated, which will not affect the fragmentation of the sandstone. However, when the accumulated strain energy of the microelement segment increases, the energy will be dissipated in the rock's crushing behavior and will be transformed into other forms of energy such as the rock's damage crushing energy and the kinetic energy of the crushed rock. Combining the above equation, the unit time and unit volume in the microelement segment are integrated with equation (18) and further simplified to obtain equation (19):

$$
\sigma=E \varepsilon+\rho_{0} v^{2} r_{g}^{2}\left(\frac{\partial \varepsilon}{\partial t}\right)^{2}
$$

When the change rate of the strain rate is small, $\rho_{0} v^{2} r_{g}^{2}(\partial \varepsilon / \partial t)^{2}$ in equation (19) can be ignored. Therefore, when the strain rate is constant, the force on both ends of the sandstone specimen under impact load is a pair of equilibrium forces.

Through theoretical analysis, the basic parameters of the dynamic mechanics and the expression of dynamic energy of sandstone under impact load are obtained, and the feasibility of processing dynamic mechanics data based on the threewave method is verified theoretically. In addition, to ensure the reliability of the test, it is necessary to verify the stress balance of the sandstone specimen under the impact load. Figure 5 shows the typical stress balance test curve of the sandstone specimen. By testing the stress balance, the stress on the specimen conforms to the stress balance assumption. Also, it can be found that the stress balance at both ends of the specimen can be satisfied, which shows that the processing and placement of the sandstone specimen meet the SHPB one-dimensional stress wave assumption, end friction, and inertial effect requirements. This also shows that the experimental results obtained through the SHPB device in this experiment are reliable.

\section{Results and Analysis}

4.1. Analysis of Static Mechanical Test Results. For the sake of grasping the static mechanical properties of the damaged sandstone more comprehensively and explaining the law of dynamic mechanics better, this test carries out static loading tests on sandstones with different degrees of damage to explore the static mechanical properties of the damaged sandstone. By loading 6 nondestructive sandstones and taking the average value of the strength of the sandstone specimens, the uniaxial compressive strength $\sigma_{b}$ of the sandstone is $60.21 \mathrm{MPa}$. Then, the nondestructive sandstone is treated with different degrees of damage by different cyclic load thresholds. The cyclic load thresholds are $0.2 \sigma_{b}, 0.4 \sigma_{b}$, $0.6 \sigma_{b}$, and $0.8 \sigma_{b}$, respectively, and the number of cyclic loadings for each sandstone specimen is 10 times. Therefore, from the perspective of stress history, the damage degree of these sandstones is $20 \%, 40 \%, 60 \%$, and $80 \%$, respectively. Each group selected 6 standard cylindrical specimens for static mechanical strength test. The results are shown in Table 1.

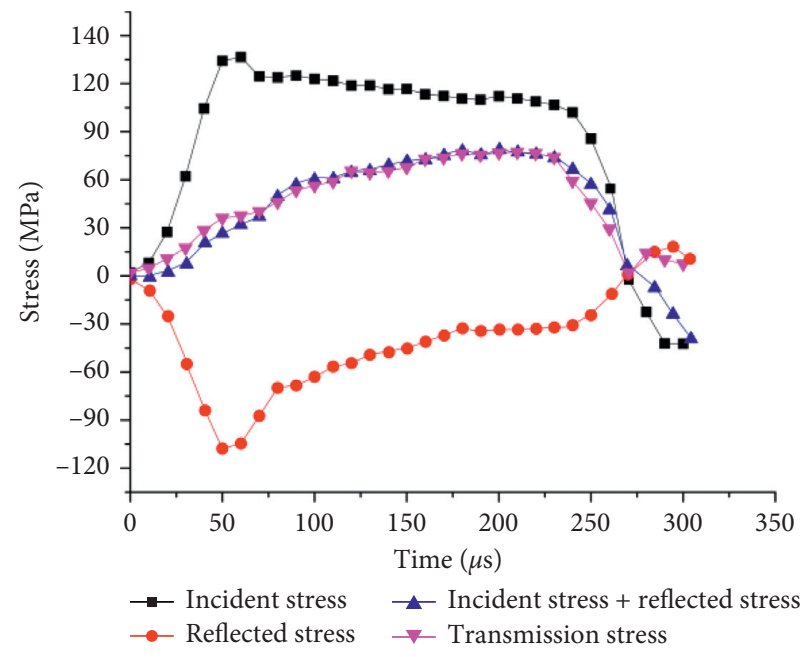

FIgURE 5: Stress balance test of sandstone specimen.

TABLE 1: Uniaxial compressive strength of sandstone specimens with different degrees of damage.

\begin{tabular}{|c|c|c|c|}
\hline $\begin{array}{l}\text { Cyclic load } \\
\text { threshold }\end{array}$ & Number & $\begin{array}{l}\text { Stress } \\
(\mathrm{MPa})\end{array}$ & $\begin{array}{l}\text { Average stress } \\
(\mathrm{MPa})\end{array}$ \\
\hline \multirow{6}{*}{$0.2 \sigma_{b}$} & 1 & 59.83 & \multirow{6}{*}{58.97} \\
\hline & 2 & 59.21 & \\
\hline & 3 & 60.02 & \\
\hline & 4 & 56.19 & \\
\hline & 5 & 57.38 & \\
\hline & 6 & 61.21 & \\
\hline \multirow{6}{*}{$0.4 \sigma_{b}$} & 1 & 58.04 & \multirow{6}{*}{55.76} \\
\hline & 2 & 54.52 & \\
\hline & 3 & 55.38 & \\
\hline & 4 & 58.73 & \\
\hline & 5 & 53.68 & \\
\hline & 6 & 54.22 & \\
\hline \multirow{6}{*}{$0.6 \sigma_{b}$} & 1 & 42.45 & \multirow{6}{*}{45.57} \\
\hline & 2 & 48.62 & \\
\hline & 3 & 45.77 & \\
\hline & 4 & 47.73 & \\
\hline & 5 & 44.85 & \\
\hline & 6 & 44.01 & \\
\hline \multirow{6}{*}{$0.8 \sigma_{b}$} & 1 & 25.74 & \multirow{6}{*}{26.86} \\
\hline & 2 & 26.43 & \\
\hline & 3 & 22.98 & \\
\hline & 4 & 30.88 & \\
\hline & 5 & 28.41 & \\
\hline & 6 & 26.73 & \\
\hline
\end{tabular}

According to the results, the stress reduction ratio of damaged sandstone is $2.06 \%, 7.40 \%, 24.31 \%$, and $55.39 \%$, respectively, after 10 cycles of stress values of $0.2 \sigma_{b}, 0.4 \sigma_{b}$, $0.6 \sigma_{b}$, and $0.8 \sigma_{b}$, respectively. The uniaxial compressive strength of damaged sandstone decreases with the increase of the degree of damage, and the magnitude of the decrease gradually increases with the increase of the degree of damage. Fitting the cyclic load threshold ratio of the damaged sandstone to the strength reduction ratio is shown in Figure 6. 


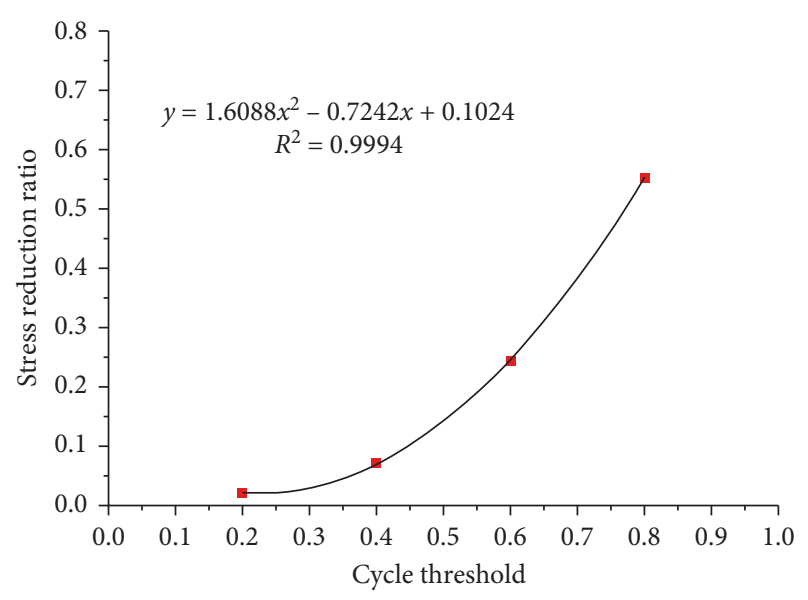

FIGURE 6: The relationship between stress reduction ratio and damage degree of sandstone.

From the fitting results, the fitting curve of the cyclic load threshold and the stress reduction ratio of damaged sandstone is $y=1.6088 x^{2}-0.7242 x+0.1024$, and the fitting degree $R^{2}$ is 0.9994 , indicating that the fitting degree is very good. From the fitting function, it can also be concluded that the uniaxial compressive strength of the damaged sandstone decreases with the increase of the cyclic load threshold, and the higher the degree of damage, the faster the strength decreases, which is related to the mechanical properties of the sandstone.

When the cyclic load threshold is less than $0.4 \sigma_{b}$, the mechanical characteristics in the sandstone mainly show the compaction and elastic deformation of the primary pores [21], and the deformation-resistant bearing medium in the sandstone is mainly solid mineral particles [22]; at this stage, the deformation of the inner sandstone can be mostly recovered with the removal of the external force, and only a small amount of deformation cannot be recovered. In the meantime, the number of cracks in the sandstone is small and the scale is small [23]. Therefore, the strength of the sandstone has not lost much, and the uniaxial compressive strength of the damaged sandstone has a smaller decrease. When the cyclic load threshold reaches $0.6 \sigma_{b}$, a random distribution of cracks occurs in the sandstone specimen [24]. The cracks have not yet penetrated, but the number of cracks generated in the sandstone under the action of the first two cyclic load thresholds is larger and the scale is larger. At the same time, the ratio of plastic deformation of sandstone is also greater than that of the first two stages, and the reduction of sandstone strength is also greater. Compared with the first two cycle thresholds, the reduction of uniaxial compressive strength is significantly increased. Continuing to increase the cyclic load threshold until $0.8 \sigma_{b}$, there are more cracks in the sandstone than in the first three stages, and some cracks have formed through [25], but the main crack of the sandstone has not yet penetrated, so the sandstone at this time still has some carrying capacity. Compared with the first three stages, the proportion of unrecoverable deformation reached the maximum after removing the external force. Therefore, the uniaxial compressive strength of the damaged sandstone under this cyclic load threshold is the largest and the fastest.

Analyzing the static mechanical properties of the damaged sandstone, it can be found that as the cyclic load threshold increases, the stress reduction ratio of the damaged sandstone increases monotonically with a quadratic function, and the growth rate gradually increases. By analyzing the mechanical mechanism of the damaged sandstone, the structural changes in the damaged sandstone at different degrees are mastered and matched with the macroscopic mechanical properties. So how do these changes in internal structure affect the dynamic mechanical properties of damaged sandstone? What is the change law of dynamic mechanical properties? Next, we explore by analyzing impact dynamics experiments.

4.2. Analysis of Dynamic Mechanical Test Results. By analyzing the dynamic mechanical properties of sandstone specimens with different degrees of damage, it can be found that the dynamic mechanical properties of sandstones with different degrees of damage are consistent when the impact gas pressure is $0.3 \mathrm{MPa}, 0.4 \mathrm{MPa}$, and $0.5 \mathrm{MPa}$. Due to space limitation, this paper only analyzes the dynamic mechanical properties of damaged sandstone when the impact gas pressure is $0.4 \mathrm{MPa}$ to explore the dynamic mechanical properties of sandstone damaged by different cyclic load thresholds. After processing the dynamic mechanical parameters with the three-wave method, the dynamic stress values of different damaged sandstones are obtained, and the energy of the damaged sandstones is analyzed and calculated. The result statistics are shown in Table 2.

It can be seen from the test results that although the damage degree of sandstone is different under different cyclic loads, the dynamic strength is increased compared to the static mechanical strength. Combining the above static mechanical properties and changes in the sandstone internal structure with different degrees of damage, the stress reduction ratio of damaged sandstone increases with the increase of the cyclic load threshold, and the stress reduction ratio is a unary quadratic function about the cyclic load threshold. Does the relationship between the dynamic stress reduction ratio of damaged sandstone and the upper limit of cyclic load follow the above-mentioned law?

Through analysis, it can be found that the dynamic compressive strength of nondestructive sandstone is $72.33 \mathrm{MPa}$. When the cyclic load thresholds are $0.2 \sigma_{b}, 0.4 \sigma_{b}$, $0.6 \sigma_{b}$, and $0.8 \sigma_{b}$, respectively, the dynamic compressive strength corresponds to $70.37 \mathrm{MPa}, 65.80 \mathrm{MPa}, 51.97 \mathrm{MPa}$, and $29.48 \mathrm{MPa}$, respectively. By comparison, it is not difficult to find that as the cyclic load threshold increases, the dynamic compressive strength of the damaged sandstone gradually decreases, which is consistent with the laws presented by static mechanics, which shows that the change of internal structure of damaged sandstone also affects its dynamic mechanical properties. Similarly, the change of the dynamic stress reduction ratio by changing the dynamic compressive strength with the cyclic load threshold is analyzed, as shown in Figure 7. At the same time, to facilitate 
TABLE 2: Energy statistics of sandstones with different degrees of damage under impact load.

\begin{tabular}{|c|c|c|c|c|c|c|c|c|c|}
\hline \multirow[t]{2}{*}{ Cyclic load threshold } & \multicolumn{2}{|c|}{$\begin{array}{l}\text { Specimen size } \\
(\mathrm{mm})\end{array}$} & \multirow[t]{2}{*}{$\sigma_{d}(\mathrm{MPa})$} & \multirow[t]{2}{*}{ Average of $\sigma_{d}(\mathrm{MPa})$} & \multirow[t]{2}{*}{$W_{i}(\mathrm{~J})$} & \multirow[t]{2}{*}{$W_{t}(\mathrm{~J})$} & \multirow[t]{2}{*}{$W_{r}(\mathrm{~J})$} & \multirow[t]{2}{*}{$\omega_{s}\left(\mathrm{~J} \cdot \mathrm{cm}^{-3}\right)$} & \multirow[t]{2}{*}{ Average of $\omega_{s}\left(\mathrm{~J} \cdot \mathrm{cm}^{-3}\right)$} \\
\hline & Diameter & Height & & & & & & & \\
\hline \multirow{3}{*}{0} & 49.75 & 24.68 & 69.98 & \multirow{3}{*}{72.33} & 108.64 & 11.75 & 40.38 & 1.1779 & \multirow{3}{*}{1.1779} \\
\hline & 50.04 & 25.61 & 72.83 & & 106.43 & 14.27 & 33.63 & 1.1621 & \\
\hline & 49.84 & 26.06 & 74.17 & & 107.52 & 11.96 & 37.49 & 1.1422 & \\
\hline \multirow{3}{*}{$0.2 \sigma_{b}$} & 49.92 & 24.76 & 68.89 & \multirow{3}{*}{70.37} & 106.68 & 12.26 & 46.56 & 0.9876 & \multirow{3}{*}{0.9876} \\
\hline & 49.95 & 25.09 & 71.57 & & 108.47 & 10.88 & 48.67 & 0.9950 & \\
\hline & 50.02 & 25.11 & 70.56 & & 106.82 & 10.37 & 47.24 & 0.9973 & \\
\hline \multirow{3}{*}{$0.4 \sigma_{b}$} & 49.94 & 24.64 & 66.69 & \multirow{3}{*}{65.80} & 101.06 & 8.02 & 47.67 & 0.9400 & \multirow{3}{*}{0.9400} \\
\hline & 49.88 & 25.12 & 67.91 & & 104.90 & 7.55 & 50.37 & 0.9571 & \\
\hline & 50.04 & 24.94 & 62.81 & & 101.98 & 7.67 & 48.74 & 0.9290 & \\
\hline \multirow{3}{*}{$0.6 \sigma_{b}$} & 50.04 & 25.05 & 48.37 & \multirow{3}{*}{51.97} & 110.24 & 4.87 & 68.84 & 0.7415 & \multirow{3}{*}{0.7415} \\
\hline & 49.96 & 24.85 & 54.15 & & 103.65 & 5.23 & 61.21 & 0.7638 & \\
\hline & 49.97 & 26.12 & 53.39 & & 100.66 & 4.35 & 58.11 & 0.7457 & \\
\hline \multirow{3}{*}{$0.8 \sigma_{b}$} & 50.01 & 25.13 & 29.89 & \multirow{3}{*}{29.48} & 103.73 & 2.29 & 69.53 & 0.6464 & \multirow{3}{*}{0.6464} \\
\hline & 49.95 & 26.22 & 31.47 & & 108.47 & 2.75 & 70.88 & 0.6780 & \\
\hline & 49.95 & 24.06 & 27.09 & & 108.84 & 3.32 & 75.94 & 0.6274 & \\
\hline
\end{tabular}

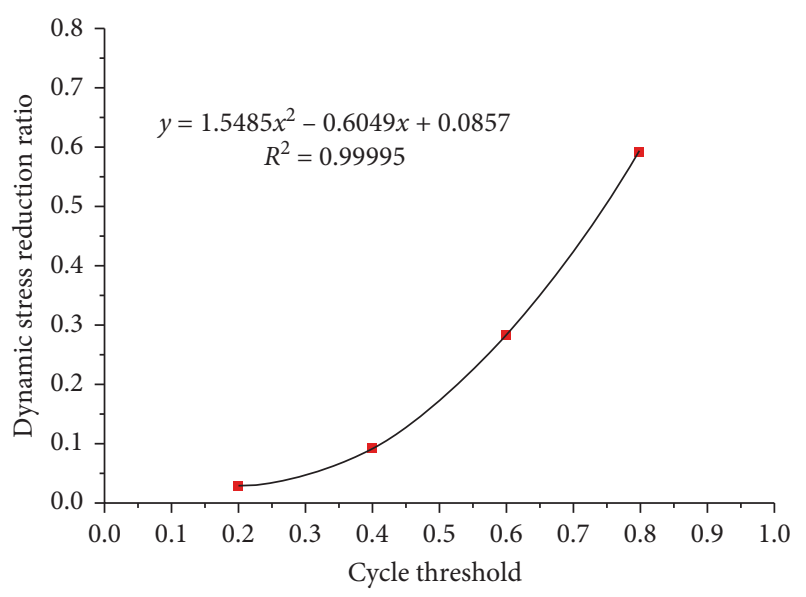

FIgURE 7: The relationship between dynamic stress reduction ratio and damage degree of sandstone.

the analysis, the dynamic strength increase factor (DIF), the ratio of dynamic mechanical strength to static mechanical strength, is introduced [26], as shown in equation (20), and the calculation results are shown in Table 3:

$$
\mathrm{DIF}=\frac{\sigma_{d}}{\sigma_{b}},
$$

where $\sigma_{d}$ represents the dynamic compressive strength of sandstone and $\sigma_{b}$ represents the static compressive strength of sandstone.

It can be seen from the fitting results that the fitting curve is $y=1.5485 x^{2}-0.6049 x+0.0857$, and the fitting degree $R^{2}$ is 0.99995 , indicating that the dynamic compressive strength is highly fitted. From the fitting function, the law that the dynamic compressive strength of the damaged sandstone decreases with the increase of the cyclic load threshold is obtained, and the higher the degree of damage is, the faster the strength decreases. This is also consistent with the law
TABLE 3: DIF of sandstones with different degrees of damage.

\begin{tabular}{lccccc}
\hline Cyclic load threshold & 0 & $0.2 \sigma_{b}$ & $0.4 \sigma_{b}$ & $0.6 \sigma_{b}$ & $0.8 \sigma_{b}$ \\
\hline DIF & 1.2013 & 1.1933 & 1.1800 & 1.1404 & 1.0975 \\
\hline
\end{tabular}

presented by the static compressive strength of damaged sandstone.

Since the introduction of SHPB technology to China, many scholars have done a lot of experimental research on rocks and achieved fruitful results [27-30]. A large number of previous test data and related literature indicate that there is a significant strain rate effect in the elastic-brittle material; that is, the change of strain rate has a great influence on the mechanical characteristics of the material, so the strength of the elastic and brittle material under dynamic impact load is higher than the strength of the specimen measured under static conditions; that is, the dynamic strength increase factor (DIF) $>1$.

By comparison, it is not difficult to find that as the degree of damage increases, the dynamic intensity increase factor (DIF) gradually decreases, because the density of sandstone after different cyclic load thresholds is different and the number and scale of weak faces in the structure are different. According to the Griffith strength theory, under the effect of static load, these cracks with different numbers and different scales produce stress concentration due to the tip effect and are broken [31]. Therefore, the greater the damage of sandstone, the greater the number of cracks and the lower the strength. Under the impact load, the higher the strain rate, the larger the crack size and number and the more obvious the crack tip effect. Compared with the nondestructive sandstone, this phenomenon leads to the relatively weak strain rate effect and faster dynamic stress reduction of sandstone. With the increase in crack number, the ability of sandstone to accumulate energy is weakened. Before the strain energy of the sandstone is released, the energy needed to be absorbed by the specimen is less, and the more the cracks are, the more 
obvious this phenomenon is [32]. In addition, under the static load of low strain rate, the cracks in sandstone gradually expand, and then the whole sandstone is destroyed and destabilized. Under the impact load, with the combined action of strain rate effect weakening and crack tip effect, the dynamic strength of sandstone decreases faster. So, the influence of crack number and size on strength weakening is more obvious than that under static load. This is also the reason why the dynamic strength increase factor (DIF) gradually decreases as the upper limit of cyclic load increases. To verify the law of DIF reduction, through the analysis of two fitting functions, it is proved from mathematical theory, as shown in equation (21). Calculating the first derivative of the function, it is found that the function increases monotonically in the range of damage threshold, and $y$ is always greater than 0 . This shows that the dynamic stress reduction rate of damaged sandstone is faster than that of static stress reduction rate, so DIF monotonically decreases:

$$
y=y_{d}-y_{s}
$$

where $y_{d}$ is the dynamic stress reduction rate of damaged sandstone and $y_{s}$ is the static stress reduction rate of damaged sandstone.

By analyzing the dynamic stress and dynamic strength increase factor (DIF) of the damaged sandstone, the basic properties of the dynamic mechanics of the damaged sandstone are grasped, but the analysis of the dynamic mechanical properties of the damaged sandstone is not enough only by the dynamic strength. Therefore, the authors combined energy dissipation to analyze the dynamic mechanical properties and energy evolution of damaged sandstone. The energy evolution curves of sandstones with different degrees of damage over time are shown in Figures 8-12. At the same time, the statistics of the percentages of various energies in the incident energy are shown in Table 4, and the proportion of each energy in the sandstone with different degrees of damage is plotted, as shown in Figure 13.

Combined with equation (7), the energy evolution of damaged sandstones is shown in Figures 8-12. With time, the four energies of incident energy, dissipated energy, reflected energy, and transmission energy gradually increase. There is no significant change in the four energies in the initial $50 \mu \mathrm{s}$, because the stress wave is in the rising period in this range [28]. For nondestructive sandstone and low-stress cyclic loading sandstone in the stage of elastic deformation, the energy absorbed by the sandstone is mainly stored in the form of elastic energy [26]. For the damaged sandstone with $0.6 \sigma_{b}$ and $0.8 \sigma_{b}$ as the cyclic load threshold, there are many cracks in the specimen [33], and the stress wave exists in the form of reflected energy under the action of the cracks randomly distributed in the damaged sandstone. However, during the period from $50 \mu$ s to $250 \mu$ s, the growth rates of the four energies are significantly different, and the growth rates of the four energies in this phase range have reached the maximum. After $250 \mu \mathrm{s}$, the cracks inside the sandstone quickly expanded and induced new cracks until the cracks penetrated to a certain extent. At the same time, the strain

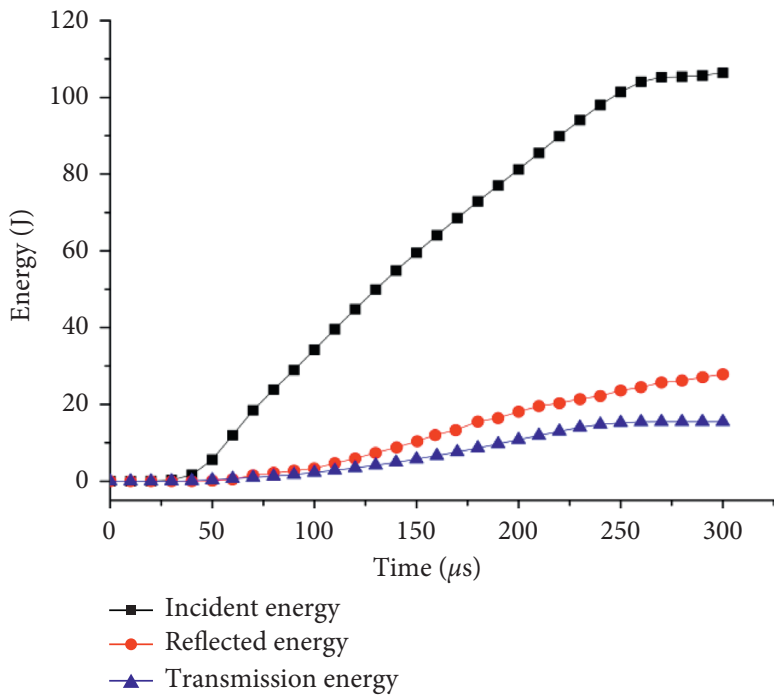

FIGURE 8: Energy evolution of nondestructive sandstone.

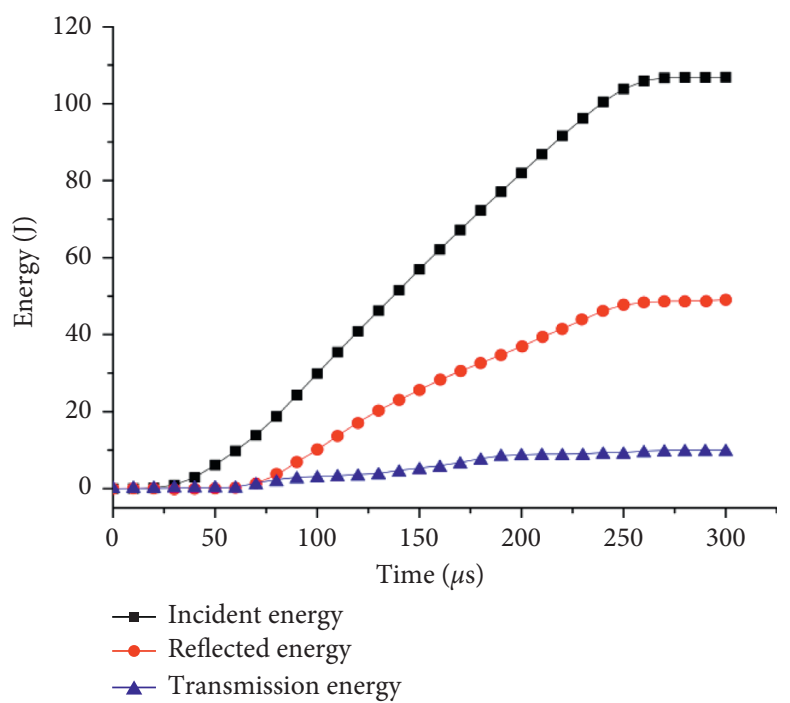

FIgURE 9: Energy evolution of sandstone with upper limit of cyclic load $0.2 \sigma_{b}$.

energy stored in the sandstone is released, which further promotes the development of ring cracks. Eventually, the four kinds of energy approach a stable value, so the energy growth rate is also smaller than the previous stage.

It can be seen from Figures 8 to 13 and Table 4 that, under the same impact pressure, the incident energy is the same, but the proportion of dissipated energy, reflected energy, and transmission energy of the sandstones with different damage levels is different. For nondestructive sandstone, the wave impedance matches the wave impedance of the incident bar. Therefore, when the stress waves reach the contact surface between the sandstone specimen and the incident bar, the reflected stress waves are small, except a small part of the stress waves which are transmitted to the transmission bar in the form of transmitted stress waves, and the rest of the stress waves are absorbed in the test 


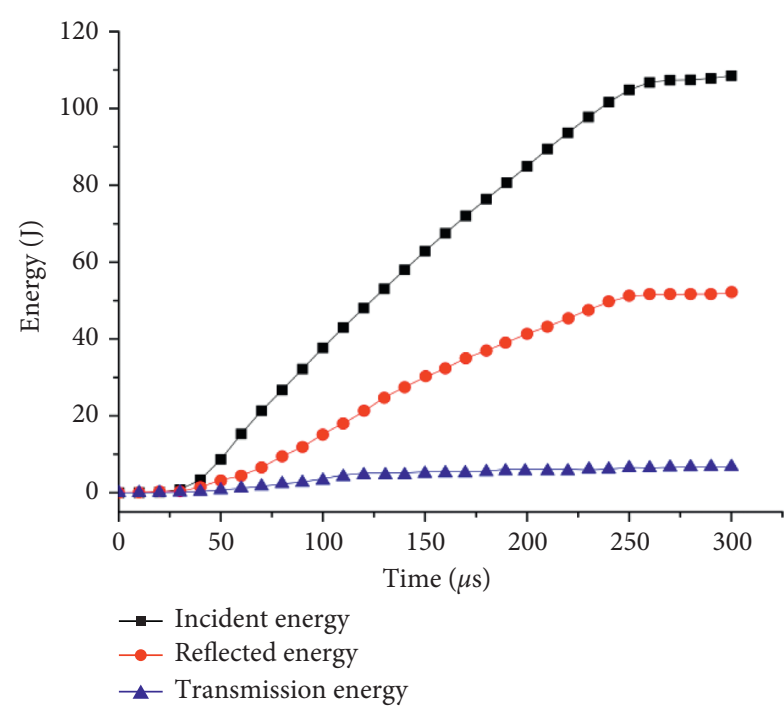

FIGURE 10: Energy evolution of sandstone with upper limit of cyclic load $0.4 \sigma_{b}$.

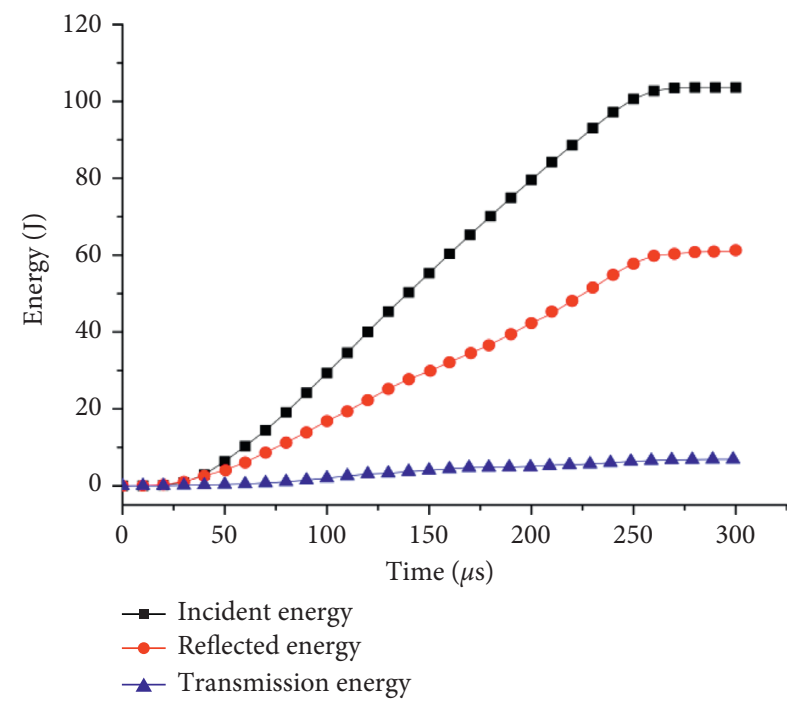

FIGURE 11: Energy evolution of sandstone with upper limit of cyclic load $0.6 \sigma_{b}$.

piece, which are used for the cracking and breaking of the sandstone specimen and are eventually dissipated in the form of energy. Therefore, the energy of the nondestructive sandstone under the impact load is mainly used in the form of dissipated energy to break the sandstone specimen, and at the same time, a certain proportion of the transmission energy is absorbed by the damper.

From the static mechanical properties of the sandstone mentioned above, the internal structure of damaged sandstone is different under different cyclic loads [20,34]. Under the cyclic load of $0.2 \sigma_{b}$ and $0.4 \sigma_{b}$, the damage of the internal structure of the damaged sandstone is very limited, the original pores are closed under the static load, and there is local deterioration in the sandstone in the closed area. On the one hand, despite the primary pores that are compacted

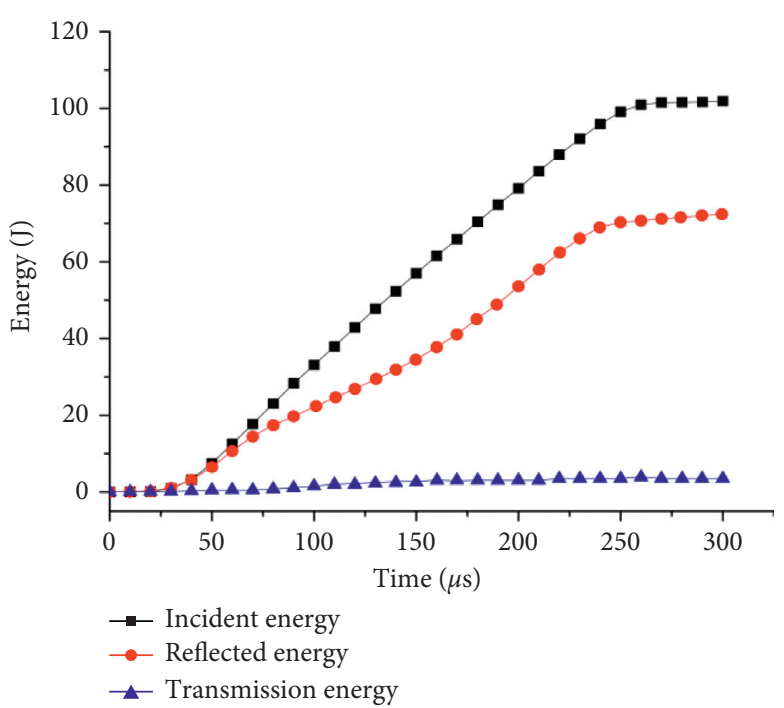

FIGURE 12: Energy evolution of sandstone with upper limit of cyclic load $0.8 \sigma_{b}$.

TABle 4: Energy ratio of sandstones with different degrees of damage under impact load.

\begin{tabular}{lccc}
\hline $\begin{array}{l}\text { Cyclic load } \\
\text { threshold }\end{array}$ & $\begin{array}{c}\text { Ratio of } W_{t} \\
(\%)\end{array}$ & $\begin{array}{c}\text { Ratio of } W_{r} \\
(\%)\end{array}$ & $\begin{array}{c}\text { Ratio of } W_{s} \\
(\%)\end{array}$ \\
\hline 0 & 11.78 & 37.55 & 50.67 \\
$0.2 \sigma_{b}$ & 9.41 & 42.25 & 48.34 \\
$0.4 \sigma_{b}$ & 7.55 & 47.66 & 44.79 \\
$0.6 \sigma_{b}$ & 4.60 & 62.73 & 32.66 \\
$0.8 \sigma_{b}$ & 2.60 & 67.38 & 30.02 \\
\hline
\end{tabular}

and closed, the free faces on both sides are pressed against each other and closed, but it does not change the fact that there are weak faces at the closed primary pores area. On the other hand, under the action of low-stress cyclic load, although the rock is mainly elastically deformed, some new cracks still occur, which are also weak faces [20]. Under the impact load, the stress waves transmit and reflect when they reach the contact face of the specimen and the weak faces in the specimen, and the weak surface in the damaged sandstone is not in the same plane but randomly distributed in the damaged sandstone [35]. Therefore, when passing through any plane with weak faces, reflection and transmission occur, and the weaker the faces are, the greater the number of reflections is, which results in large reflection energy and a small transmission energy. Also, when a cyclic load of $0.4 \sigma_{b}$ is applied to a sandstone specimen, the weak faces generated inside are slightly more than that generated by the cyclic load of $0.2 \sigma_{b}$. But since they are also in the elastic stage, there is no obvious difference in quantity, only a small increase [36]. Therefore, when the upper limit of the cyclic load is $0.2 \sigma_{b}$ and $0.4 \sigma_{b}$, the reflection and transmission of the stress waves are not much different. The cyclic load of $0.4 \sigma_{b}$ is only a small increase from the reflected stress waves of $0.2 \sigma_{b}$.

Under the above two cyclic loads, there are no obvious cracks in the sandstone. So, the energy change is small compared to nondestructive sandstone. As the cyclic load 


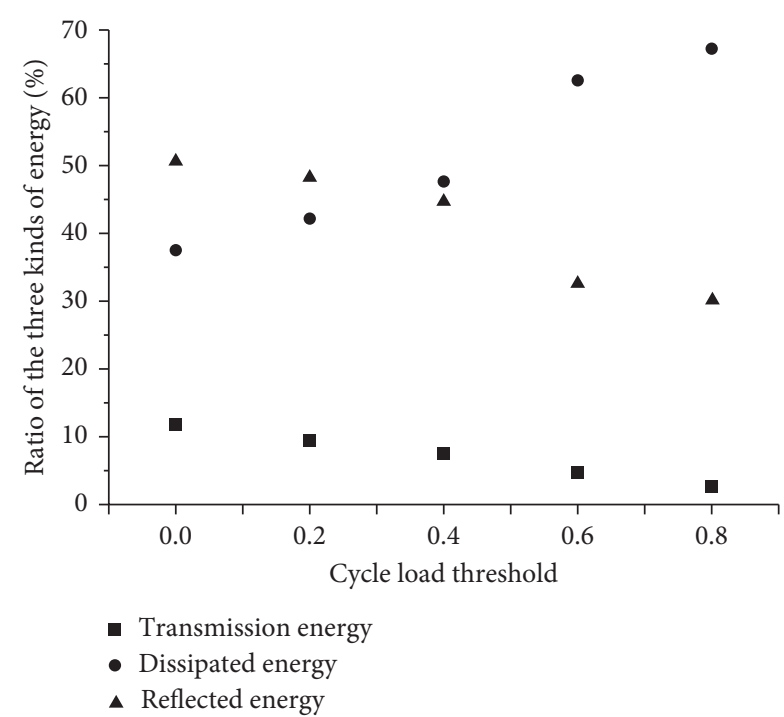

FIGURE 13: The proportion of the three energies to the incident energy at different cyclic thresholds.

threshold increases to $0.6 \sigma_{b}$, the number of cracks generated in the sandstone is larger and the scale is larger. At this time, the cracks are randomly distributed in the damaged sandstone. When the stress waves encounter such cracks that are larger in scale and more in number, the stress waves generate a greater proportion of reflection and a smaller proportion of transmission. With the continuous increase of the cyclic load threshold until $0.8 \sigma_{b}$, the cracks randomly distributed in the damaged sandstone have formed penetration, but the main crack has not yet penetrated. Therefore, the sandstone is still intact macroscopically, but the densely interlaced cracks have caused the sandstone at this time to lose most of its bearing capacity. When stress waves propagate to such sandstone specimens, there are very few transmitted waves, and most of them exist in the form of reflected waves.

In summary, when the impact load acts on the nondestructive sandstone, there are almost no cracks inside and the required braking energy is the largest, and because there is no weak face, the transmission energy is also the largest. At this time, the incident energy is mainly used to break the sandstone specimen. Damaged sandstones under the action of two cyclic load thresholds of $0.2 \sigma_{b}$ and $0.4 \sigma_{b}$ have similar internal structures, so the proportions of various energies are very close, but the latter has a slightly smaller dissipated energy than the former. Due to the presence of partial damage, the energy required to break the damaged sandstone is less than that of the nondestructive sandstone. From this, it can be found that the greater the degree of damage, the smaller the dissipated energy required when the damaged sandstone is broken under the impact load. Therefore, as the threshold of cyclic load increases, the proportion of dissipated energy gradually decreases. Similarly, as the degree of damage increases, the number and proportion of weak surfaces in the damaged sandstone gradually increase, the proportion of reflected stress waves gradually increases, and the proportion of transmitted stress waves gradually decreases. Therefore, as the degree of damage increases, the proportion of reflected energy gradually increases, and the transmitted energy gradually decreases.

\section{Discussion}

Under the impact load, the destruction process of sandstone is closely related to energy evolution. Theoretically, under the same impact pressure, the destruction law of sandstone is approximately the same. Based on Kaiser effect of the rock, the authors combined it with the actual situation of the project and treated the sandstone with different cyclic load thresholds to make the sandstone in different degrees of damage. The static mechanical properties and internal structure differences of damaged sandstone after cyclic loading are analyzed, and the differences in dynamic mechanical properties are further analyzed. It is also because of the different internal structure of sandstone damaged by a static load, which leads to different dynamic strength enhancement factors of sandstone with different degrees of damage. Under the effect of impact load, reflection and transmission of stress waves in different degrees and proportions occur during the propagation, due to different number and scale of cracks in sandstones with different degrees of damage. At the same time, the energy absorbed by sandstones with different damage levels is also different. This also makes the dissipation energy required for sandstone damage with different damage levels different under the same incident energy, which also causes the difference in the proportion of reflected energy and incident energy. In coal mines with a high tendency to rock burst, by analyzing the law of energy evolution of the rock under the impact load, it can be found that as the damage degree increases, the proportion of dissipated energy decreases and the proportion of reflected energy increases. That is, less energy is used to break the rock, but the proportion of reflected energy which has increased should also be noted. Since the effect of reflection and stretching is strong on the brittle materials such as rocks, when studying dynamic disasters such as rock bursts, the damage degree of the rock should be combined, the relative relationship between the transmitted energy and the dissipated energy under the impact load should be explored, and the types of dynamic disasters should be analyzed for formulating a more reasonable solution to the danger and preventive measures. By systematically studying the dynamic mechanical properties and energy evolution laws of sandstones with different damage degrees, it provides a certain reference for the research and prevention of the treatment of rock burst mechanism.

\section{Conclusion}

(1) The sandstones under different cyclic loading thresholds are in different degrees of damage. The stress reduction ratio and the dynamic stress reduction ratio of the uniaxial compressive strength of damaged sandstone increase with the increase of the cyclic load threshold, and the two are unary quadratic functions about the cyclic load threshold. 
(2) Under the same impact pressure, the dynamic strength increase factor (DIF) of the damaged sandstone is greater than 1 , and it decreases with the increase of the cyclic load threshold.

(3) Under the condition of a certain impact load, due to the difference in the number and scale of cracks in the sandstone with different degrees of damage, under the comprehensive effect of cracks, the dissipated energy density per unit volume of the damaged sandstone decreases with the increase of the cyclic load threshold, and the change law of reflected energy is the opposite of the threshold.

(4) In coal mines with a rock burst tendency of medium or higher hazard level, especially deep coal mines, the damage degree of the rock mass should be analyzed first, and then the correlation between transmission energy and dissipated energy should be determined according to its impact dynamics performance, the cause of dynamic disasters should be analyzed, and reasonable measures should be taken to resolve the danger.

\section{Data Availability}

The experimental data used to support the findings of this study are included within the article.

\section{Conflicts of Interest}

The authors declare no conflicts of interest regarding the publication of this paper.

\section{Acknowledgments}

This work was funded by the Natural Science Foundation of Anhui Province (nos. 1908085QE226, 1908085QE186, and 1908085QE184) and Science Research Foundation for Young Teachers of Anhui University of Science and Technology (no. QN2018117).

\section{References}

[1] W.-m. Cheng, W. Nie, G. Zhou, Y. Yu, Y. Ma, and J. Xue, "Research and practice on fluctuation water injection technology at low permeability coal seam," Safety Science, vol. 50, no. 4, pp. 851-856, 2012.

[2] A.-y. Cao, L.-m. Dou, C.-b. Wang, X.-x. Yao, J.-y. Dong, and Y. Gu, "Microseismic precursory characteristics of rock burst hazard in mining areas near a large residual coal pillar: a case study from Xuzhuang coal mine, Xuzhou, China," Rock Mechanics and Rock Engineering, vol. 49, no. 11, pp. 44074422, 2016.

[3] J. He, L. Dou, S. Gong, J. Li, and Z. Ma, "Rock burst assessment and prediction by dynamic and static stress analysis based on micro-seismic monitoring," International Journal of Rock Mechanics and Mining Sciences, vol. 93, pp. 46-53, 2017.

[4] X. S. Liu, J. G. Ning, Y. L. Tan, Q. Xu, and D. Y. Fan, "Coordinated supporting method of gob-side entry retaining in coal mines and a case study with hard roof," Geomechanics and Engineering, vol. 15, no. 6, pp. 1173-1182, 2018.
[5] S. C. Hu, Y. L. Tan, J. G. Ning, W. Y. Guo, and X. S. Liu, "Multiparameter monitoring and prevention of fault-slip rock burst," Shock and Vibration, vol. 2017, Article ID 7580109, 8 pages, 2017.

[6] J. Wang, J. G. Ning, P. Q. Qiu, S. Yang, and H. F. Shang, "Microseismic monitoring and its precursory parameter of hard roof collapse in longwall faces: a case study," Geomechanics and Engineering, vol. 17, no. 4, pp. 375-383, 2019.

[7] Y. L. Tan, X. S. Liu, B. Shen, Q. H. Gu, and J. G. Ning, "New approaches to testing and evaluating the rockburst risk of coal seam with hard roof and/or floor in coal mines," Geomechanics and Engineering, vol. 14, no. 4, pp. 367-376, 2018.

[8] Z. Khademian and O. Ugur, "Computational framework for simulating rock burst in shear and compression," International Journal of Rock Mechanics and Mining Sciences, vol. 110, pp. 279-290, 2018.

[9] C. Tian, X. Yang, H. Sun, Y. Liu, and Q. Hu, "Experimental study on the overburden movement and stress evolution in multi-seam mining with residual pillars," Energy Science \& Engineering, vol. 7, no. 6, pp. 3095-3110, 2019.

[10] B. P. Simser, "Rockburst management in Canadian hard rock mines," Journal of Rock Mechanics and Geotechnical Engineering, vol. 11, no. 5, pp. 1036-1043, 2019.

[11] W. Cai, L. Dou, G. Si et al., "A new seismic-based strain energy methodology for coal burst forecasting in underground coal mines," International Journal of Rock Mechanics and Mining Sciences, vol. 123, p. 104086, 2019.

[12] W. J. Gale, "A review of energy associated with coal bursts," International Journal of Mining Science and Technology, vol. 28, no. 5, pp. 755-761, 2018.

[13] G. Wang, F. Jin, S. Gong, L. Dou, C. Cai, and X. Yuan, "Generating behaviors of strong tremors and experimental study of rockburst-triggering criterion," Shock and Vibration, vol. 2019, Article ID 6319612, 12 pages, 2019.

[14] Z. Zhou, X. Cai, X. Li, W. Cao, and X. Du, "Dynamic response and energy evolution of sandstone under coupled static-dynamic compression: insights from experimental study into deep rock engineering applications," Rock Mechanics and Rock Engineering, vol. 53, no. 3, pp. 1305-1331, 2020.

[15] M. Rehbock-Sander and T. Jesel, "Fault induced rock bursts and micro-tremors-experiences from the Gotthard base tunnel," Tunnelling and Underground Space Technology, vol. 81, pp. 358-366, 2018.

[16] A. Sainoki, M. Z. Emad, and H. S. Mitri, "Study on the efficiency of destress blasting in deep mine drift development," Canadian Geotechnical Journal, vol. 54, no. 4, pp. 518-528, 2017.

[17] M. C. He, J. L. Miao, and J. L. Feng, "Rock burst process of limestone and its acoustic emission characteristics under truetriaxial unloading conditions," International Journal of Rock Mechanics and Mining Sciences, vol. 47, no. 2, pp. 286-298, 2010.

[18] C.-P. Lu, G.-J. Liu, Y. Liu, N. Zhang, J.-H. Xue, and L. Zhang, "Microseismic multi-parameter characteristics of rockburst hazard induced by hard roof fall and high stress concentration," International Journal of Rock Mechanics and Mining Sciences, vol. 76, pp. 18-32, 2015.

[19] Z. J. Wen, X. Wang, Y. L. Tan, H. L. Zhang, W. P. Huang, and Q. H. Li, "A study of rockburst hazard evaluation method in coal mine," Shock and Vibration, vol. 2016, Article ID 8740868, 9 pages, 2016.

[20] S. L. Song, X. S. Liu, Y. L. Tan, D. Y. Fan, Q. Ma, and H. L. Wang, "Study on failure modes and energy evolution of 
coal-rock combination under cyclic loadin," Shock and Vibration, vol. 2020, Article ID 5731721, 16 pages, 2020.

[21] J. A. Hudson and X.-T. Feng, "Technical auditing of rock mechanics modelling and rock engineering design," International Journal of Rock Mechanics and Mining Sciences, vol. 47, no. 6, pp. 877-886, 2010.

[22] D. A. Mohammed, S. A. Nabavi, and V. Manovic, " $\mathrm{CO}_{2}$-brinerock interactions: the effect of impurities on grain size distribution and reservoir permeability," International Journal of Greenhouse Gas Control, vol. 78, pp. 168-176, 2018.

[23] W. Wu, "Slip initiation of granular gouge friction in a rock discontinuity induced by static and dynamic loads," International Journal of Rock Mechanics and Mining Sciences, vol. 80, pp. 196-201, 2015.

[24] R. E. Goodman, Introduction to Rock Mechanics, Wiley, New York, NY, USA, 1980.

[25] A. Bolla and P. Paronuzzi, "Numerical investigation of the pre-collapse behavior and internal damage of an unstable rock slope," Rock Mechanics and Rock Engineering, vol. 53, no. 5, pp. 2279-2300, 2019.

[26] J. E. Field, S. M. Walley, W. G. Proud, H. T. Goldrein, and C. R. Siviour, "Review of experimental techniques for high rate deformation and shock studies," International Journal of Impact Engineering, vol. 30, no. 7, pp. 725-775, 2004.

[27] F. Dai, S. Huang, K. Xia, and Z. Tan, "Some fundamental issues in dynamic compression and tension tests of rocks using split Hopkinson pressure bar," Rock Mechanics and Rock Engineering, vol. 43, no. 6, pp. 657-666, 2010.

[28] H. Du, F. Dai, K. Xia, N. Xu, and Y. Xu, "Numerical investigation on the dynamic progressive fracture mechanism of cracked chevron notched semi-circular bend specimens in split Hopkinson pressure bar tests," Engineering Fracture Mechanics, vol. 184, pp. 202-217, 2017.

[29] W. C. Zhu, Y. Bai, X. B. Li, and L. L. Niu, "Numerical simulation on rock failure under combined static and dynamic loading during SHPB tests," International Journal of Impact Engineering, vol. 49, pp. 142-157, 2012.

[30] X. Li, Y. Zou, and Z. Zhou, "Numerical simulation of the rock SHPB test with a special shape striker based on the discrete element method," Rock Mechanics and Rock Engineering, vol. 47, no. 5, pp. 1693-1709, 2014.

[31] Q. Zheng, Y. Cheng, Q. Zong, Y. Xu, F. Li, and P. Chen, "Failure mechanism of different types of shotcrete based on modified Weibull distribution model," Construction and Building Materials, vol. 224, pp. 306-316, 2019.

[32] X. B. Li, T. Zhou, D. Y. Li, and Z. W. Wang, "Experimental and numerical investigations on feasibility and validity of prismatic rock specimen in SHPB," Shock and Vibration, vol. 2016, Article ID 7198980, 13 pages, 2016.

[33] X. S. Liu, Y. L. Tan, J. G. Ning, Y. W. Lu, and Q. H. Gu, "Mechanical properties and damage constitutive model of coal in coal-rock combined body," International Journal of Rock Mechanics and Mining Sciences, vol. 110, pp. 140-150, 2018.

[34] D. Fan, X. Liu, Y. Tan et al., "Roof cutting parameters design for gob-side entry in deep coal mine: a case study," Energies, vol. 12, no. 10, p. 2032, 2019.

[35] X. Li, Z. Li, E. Wang et al., "Pattern recognition of mine microseismic (MS) and blasting events based on wave fractal features," Fractals, vol. 26, no. 3, Article ID 1850029, 2018.

[36] S. Liu, X. Li, D. Wang, M. Wu, and G. Yin, "Mechanical and acoustic emission characteristics of coal at temperature impact," Natural Resources Research, vol. 29, no. 6, pp. 1755-1772, 2020. 